\title{
Retaining Older Workers: Fields Of Action - Constituting A Comprehensive Age Management Model
}

Jana Žnidaršič, University of Ljubljana, Slovenia

Vlado Dimovski, University of Ljubljana, Slovenia

\begin{abstract}
The need to improve labor market participation of older people has gained heightened attention in recent years, especially in view of the significant demographic changes the European Union will undergo due to population aging. Besides the macroeconomic level, the implications of this trend are very present on the company level, especially through managing the aging workforce. Companies are thus introducing new approaches, policies and instruments which are supposed to foster higher employment rates of elderly through implementing active aging concept into business and HRM practice. The aim of this paper is to highlight the development of active aging initiatives within Slovenian companies where the practice of age management is still in its early stage. However, we expect that due to the aging population and the shortages on the labor market one can expect that those practices will receive more and more attention in the future. Because of age discrimination, and a longstanding culture of early exit from employment, many organizations in Slovenia, both the workplace and the community, have no experience in positively targeting older workers. Therefore, those looking to respond to workforce aging usually start from a low or non-existent base. Moreover, Slovenian employers are still often reluctant to employ older workers, either because of age stereotypes or because of some very reasonable dilemmas concerning personnel economics. With the aim to help beginners, we have developed a conceptual model, thus providing a useful base for further development of company-specific age management model that suits to the company needs the most. A key message of this paper is that when it comes to good practice, even very small changes can have a positive impact. The paper concludes with some recommendations for the future development of active aging practice, with an emphasize on new HRM approaches, policies and instruments which seem to be of extreme importance when striving to prolong working life.
\end{abstract}

Key words: aging of population, retaining older workers, active aging approach within Slovenian enterprises, HRM, personnel economics, age management, comprehensive age management model.

\section{INTRODUCTION}

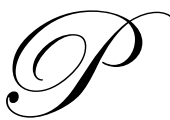

opulation aging is one of the most important challenges facing the EU, posing a threat to its macroeconomic performance and competitiveness. This demographic shift calls into question both the sustainability of pension systems and the future of Europe's labor supply, which in turn raises questions about the prospects for economic growth. In this context, increases in participation and employment rates for older workers are essential to help sustain economic growth, reinforce social cohesion and the adequacy of pensions, and manage the rising financial burden on social protection systems. However, the implications of population aging are not only present on the macroeconomic level (pensions, later retirement, health problems, etc.) but are more and more approached by the companies in public and private sector due to the aging workforce, and due to the need to adapt to older clients.

While in the "old" Member States (EU15) policies and practices - aimed at improving opportunities for older people - have developed significantly in recent years, in Slovenia, the response of policymakers, who have 
highlighted the need for initiatives to foster active aging is somehow lagging behind the EU15. Although public actors have devised policies targeting such workers, the measures have not been sufficiently specific to contribute substantially towards fostering active aging. Moreover, employers in Slovenia are still sometimes reluctant to employ older workers (Pušnik et al., 2006; Mandl, Dorr, Oberholzner, 2006). Nonetheless, the findings of some recent research do indicate that the situation is beginning to change. In particular, there appears to be a greater level of understanding of the issue at company level, especially among the larger companies. Some of them are thus introducing new approaches, policies and instruments which are synthetically called age management to accommodate to the situation of the aging workforce with the aim to provide an environment in which each individual is able to achieve his or her potential without being disadvantaged by their age. However, in striving to prolong working life in Slovenia, efforts to promote active aging must be pursued much more vigorously than within recent day-to-day practice.

With the aim to help beginners, we have developed a conceptual model, thus providing a useful base for further development of company-specific age management model that suits certain company's needs the most. The paper goes in detail presenting fields of action on the whole, offering a wide range of age management practices that could be implemented by HRM within company. The paper sheds light on the subtle connections between fields constituting a comprehensive age management model, which is beautifully presented and highlighted in its whole complexity. Moreover, it sheds light also on some economic dilemmas that are often discussed by HRM when it is about age management policies implementation.

\section{EXTREMELY LOW PARTICIPATION OF OLDER WORKERS ON SLOVENIAN LABOR MARKET IS THE FACT THAT CALLS FOR ACTION}

Slovenia shares demographic trends common to almost all European countries that encounter low and declining birth rates, a rise in life expectancy and low migration inflows of younger people. Consequently, Slovenia faces a trend of aging population and aging workforce and it is even characterized by a comparatively older population if compared to the European average: EU-25 (Eurostat, 2005).

However, the proportion of older people in the workforce is only around $25 \%$. An extremely low participation of older workers on Slovenian labor market urgently calls for immediate action. In year-group 55-64, there was only $23.5 \%$ people employed in the year 2004 (Kajzer, 2004), which was much faraway from Lisbon strategy - planning the $50 \%$ employment by the year 2010 in the same age-class, and even far from EU-15 average, which was $41.7 \%$ and EU-25 with $40.2 \%$. In Slovenia the employment rate of older people increased by 6.3 p. p. in 2004, compared to 2000 (Jouhette, Romans, 2005). However, in 2005 the share of those being employed in the yeargroup 55-64 was still low, $30.7 \%$ (the last data from 2006 is $33 \%$; European Commission, 2007), with only $18.5 \%$ of women being employed (Jouhette, Romans, 2006).

Among the complexity of reasons, one reason for the low employment rate of the elderly population can be found within the transition processes in the 1990s. The majority of workforce redundancies were older workers; however those redundancies were hidden behind the early retirements. Eighteen years ago, at the beginning of the conversion of the socialist economy to a market economy, the number of pensioners increased significantly. Amongst them, numerous pre-pensioners served the purpose of buying social peace. For too long older workers have been the adjustment variable in reorganizations.

Besides transition, there are many other reasons that hinder older workers from staying active, such as: (1) bed labor market flexibility, which is one of the most significant reasons for early retirements, since Slovenia has less than $10 \%$ of working-population, being part-time employed (Kajzer, 2005); (2) the employers' perception of older workers in our country is actually very influenced by different stereotypes and myths - the age group around 50 years and over seems to have quite limited job opportunities and it is widely deemed unattractive as a source of labor due to following reasons: a perceived lack of flexibility and initiative; a poor grasp of foreign languages; a reluctance to take part in training; limited adaptability to new working conditions; a lack of knowledge of new technologies or production processes; and a greater tendency towards taking sick leave. 
As a result, there are a huge number of unemployed people in "risk groups" such as those aged over 45 . Their share represents nearly a half of all unemployed persons. Only a few employers are aware of the fact, that (early) dismissal of the older population as a potential workforce represents a premature and permanent loss of human capital, as older people could represent a rich source of skills and experience.

Only recently, managers became aware of the need to break these bad habits. Since then new institutional and legal possibilities have been adopted, however not being efficient very much in solving the problem of the employment of seniors, since the employment rate of old people is still very low. This fact pinpoints the necessity of specific public and private initiative aimed at improving the integration of older persons in the labor market. It also pinpoints the necessity of further developing active aging within Slovenian companies.

\section{AGE MANAGEMENT DRIVERS IN SLOVENIAN COMPANIES}

The drivers which make age management practices reasonable are more or less the same within European countries. One of the main reasons that force employers to combat age barriers is age discrimination, which has been called the last unrecognized discrimination, including both open and hidden forms (Walker, 1998). For example, older workers are experiencing more long-term unemployment and get less training than younger ones.

At the same time there is a plethora of scientific evidence to show that older workers are no less effective than younger ones - though of course there are variations between jobs. Older staff also has fewer accidents than younger ones and are less likely to leave an organization. Their average net cost to an employer is similar to that of younger staff or very often cost-benefit analysis talks in favor of older employees (Brooke, 2003). In addition there are pragmatic reasons why the social partners are beginning to look for ways of removing or reducing the impact of age barriers. Some employers have even begun to articulate a 'business' case in favor of older workers. Some main reasons - why tackle age barriers include (Walker, 1998): (1) the age structure of the workforce is changing rapidly in all countries. That fact implies a radical change in human resource strategies and a new approach to managing age at the workplace. Future competitiveness will rest partly on the performance and productivity of aging workforces and, therefore, on the efficient utilization of older workers; (2) at plant level employers are reassessing the consequences of early exit. It is being seen by some as a waste of experience and human resources and of the investment they have made in the workforce. Others see roles for older workers in training younger people or in preventing skill shortages; (3) there is growing awareness among employers and trade unions that, by artificially limiting the field of candidates, age barriers prevent an organization from maximizing its recruitment potential; (4) some enterprises are recognizing that the organization with a diverse age base - a mixture of youth and maturity - is likely to be able to respond best to rapidly changing circumstances. In the service sector in particular, employers are seeing the benefits of adjusting the age range of their employees to better reflect the age composition of their customers; (5) there are widespread government concerns about employment rates and the financing of pensions. Especially in Slovenia the effect of early leaving employment has been even more present since Slovenia has gone through its transition period in which early retirements seemed to be the most elegant way of reducing employees.

Despite many drivers that foster age management initiatives, recent research (ex. Mandl, Dorr, Oberholzner, 2006; Dimovski, Žnidaršič, 2006; Žnidaršič, 2008) showed that managers can still be somehow skeptical about age management implementation as a sound business opportunity, especially in a global crisis period. Consequently, Slovenian employers are still often reluctant to employ older workers. Of course, many reasons for certain reluctance can be found within broad pool of biases and age stereotypes, however, there exist some very reasonable ones, mostly concerning an economic aspect of employing older workers. That's why, after discussing fields of action that constitute the comprehensive age management model, we will also shed light on some crucial economic dilemmas that come on the surface when active aging policies are being considered to be implemented in the company.

\section{AGE MANAGEMENT IN SLOVENIAN COMPANIES: FIELDS OF ACTION}

The aging workforce phenomenon and the action employers should be considering and implementing have resulted in forming a theoretical frame, upon which the company specific age management model could be developed. 
People of different ages have different needs, qualifications and skills. The work shall be organized so that the strengths and weaknesses of workers of different ages are paid attention to. And age management means that members of various ages are taken into account as valuable. In the context of aging workforce, age management means that the employer is responsible for setting up such conditions that enable the older employees to adapt the working requirements to meet their respective phase of life. The employee shall in turn make use of the arrangements.

In spite of the fact that the individual differences increase with age, which in turn means that individual arrangements when organizing and modifying the work tasks may be necessary for employees approaching the age of retirement, we have proposed the conceptual frame for common age management model formation, consists of six main fields of action (Dimovski, Žnidaršič, 2006): (1) changing mental models and attitudes within organizations; (2) HRM in the light of aging workforce; (3) knowledge transforming management; (4) health management; (5) workplace management: ergonomics/job design (6) managing different generations.

Changing mental models and attitudes within organizations may be a vital prerequisite to the development of good practice. Certainly it is essential to achieve a comprehensive 'age awareness' strategy. The introduction of any age management actions rests on the commitment of key personnel in an organization. It is well known that, in large organizations, sometimes the desire of senior managers to create equal opportunities for older workers is thwarted by line managers with direct responsibility for recruitment and training. Older workers are often the victims of stereotyping, unfair policies, biases and prejudices, which affect older workers by premature termination of their services, denying them promotions, excluding them from learning and training opportunities, neglecting appropriate rewards for their performance etc. (Leibold, Voelpel, 2006).

This is why, a positive approach to combating ageism is very important and may include presenting evidence to line managers, supervisory staff and the workforce in general that demonstrates the benefits of employing and investing in older workers. Such evidence may include examples from within the organization or from similar ones, or may be the results of more broadly based scientific research. As well as raising awareness about the need for good practice in the recruitment and training of older workers there may be a place for special training in equal opportunities, with reference to age, or for awareness raising as to the particular needs of an aging workforce.

The key elements of a new managerial mindset about the aging workforce are (Leibold, Voelpel, 2006): (1) discarding of age bias in hiring mature workers; (2) creating a culture that embraces older workers and honors experience; (3) offering flexible work opportunities; (4) offering flexible retirement options; (5) utilization and publicization of the benefits of an aging workforce due to practical experience.

Simultaneously with changing attitudes of managers, the first step we should take is to change people's mind-set. Procedures of retirement during the past thirty years made it look as if early retirement was an untouchable attainment, but we must finally acknowledge that such is no longer the case. Baby boomers must realize that early retirement is no longer an option (Van de Casteele, 2004). Changing mental models in the heads of older employees would include persuading them about benefits they can get when they prolong their working lives. Social contacts within the company could be beneficial to the older employee to avoid another serious problem aged people sometimes experience, social isolation and dislocation, for example. It is important for elderly to incorporate the working life into their whole well-being in later phase of life.

A HRM in the light of aging workforce starts with recruiting older workers. Good practice means ensuring that older workers have either equal or special access to the available jobs and those potential applicants are not discriminated against either directly or indirectly. For example, there should be the absence of age limits and other discriminatory mechanisms in advertisements or other methods of recruitment. Age aware HRM continues with training, development and promotion. Fortunately, resent research (for ex. Brooke, 2003; Rolland, 2004) has found, that investment in training is no more costly for older workers than it is for younger ones: older workers tend to have lower turnover rates and, in addition to this, the term for return on investment in training is getting shorter. Also, contrary to popular belief, older workers also have the ability to learn new technologies as effectively as younger workers. The methods of training simply need to be adjusted to accommodate different learning patterns (Dunn, 
2005). Good practice in this field means ensuring that older workers are not neglected in training and career development that opportunities for learning are offered throughout working life that training methods are appropriate to older workers, and that positive action is taken where necessary to compensate for discrimination in the past. Especially promotion opportunities should be open to all employees, who should know that age is not a barrier and that they will not be regarded as 'too young' or 'too old'. Promotion and career development should be based on performance that you can measure and potential that is demonstrated - rather than on age or length of service.

HRM practices targeting older employees inevitably include flexible working practices, which mean giving older workers greater flexibility in their hours of work or in the timing and nature of their retirement. Of course such flexibility may benefit younger as well as older employees and especially carers (as in the case of annualized hours) but, specifically with regard to older people, such flexibility may be an important method of retaining this group in employment.

Finally, HRM needs to consider retirement pathways, aiming to encourage longer employment continuum. More and more employers are getting aware, that compulsory retirement could mean losing skilled people and affects business productivity. Why train new staff or pay higher rates for agency workers, when an existing employee, who knows your business, could do the job. Flexible retirement can be a useful way of preparing employees to handle the change between full-time work and full retirement. There are alternatives to stopping work altogether - for example reduced hours, job-sharing, part-time working. Some employees who have retired could be seeking employment again. For employer, this could involve short-term contracts, re-employment as an advisor, and temporary cover during holidays, sickness absence or busy periods. Being flexible about retirement can mean reducing capacity without losing valuable workers and their expertise.

Knowledge-transfer management seems to be one of the bases when implementing age management politics. The literature generally acknowledges that it is important for all workers, young and old alike, to upgrade their skills on a continual basis, in order to remain productive. Skills and knowledge become quickly obsolete in a growing knowledge-economy. The training of younger workers to take over leadership roles, that is, succession planning, is expected to become a priority in the near future. Consequently, for every company it is crucial to have a succession plan, which allows the organization to retain or transfer skills and knowledge that would otherwise be lost through retirement and it is often urgent to improve the transfer and retention of critical knowledge. Actually, not only are older workers capable trainees, they are also good trainers for younger workers. By allowing older workers to play mentoring and training roles, the transfer of skills and knowledge to younger generations is facilitated. Older workers are likely to play a larger role as trainers in the future, as they become a larger segment of the workforce. They are also better educated than previous cohorts, and their skills can be a continuing source of competitive advantage to many firms.

The critical success factors that comprise the framework for action necessary to capture, share and reapply knowledge before it is lost are (DeLond, 2004): (1) identifying what essential knowledge is at risk - for example by surveying all of employees annually to find out who was planning to retire and when. Projected retirement dates are multiplied against a "position risk factor," an estimate of the indispensability of an employee provided by their supervisor or manager, to produce an attrition factor that represents the level of effort and urgency needed to manage the retirement and replacement of an employee. Then, detailed succession plans are created for replacing those employees whose pending retirement date and hard-to-replace knowledge makes them particularly important to the company; (2) knowledge sharing practices, such as: after-action reviews, communities of practice, face-to-face meetings, mentoring programs, storytelling, expert referral services, training, video conferencing, interviews, written reports, etc.; (3) using information technology to enable knowledge capture, sharing and reuse; (4) developing and retaining experienced employees and (5) building a business case for knowledge retention initiatives.

Health management at workplace is becoming of central importance in prolonging working life, since health care services should meet the increasing needs of older workers. Many surveys (for ex. Ilmarinen, 2006) showed that work-related health problems are common among men and women older than 45 years of age. Consequently, the prevention of work-related symptoms and diseases is a high priority in all age groups, but new challenges face aging workers: how can they manage at work when they have chronic symptoms and diseases? What 
can occupational health experts do to prevent the early exit of those suffering from chronic health problems? It is obvious that only treating the diseases is not enough. The new challenge is to find the adjustments needed at work due to the deterioration of health. The challenges of an aging workforce for occupational health services calls for innovation in (Ilmarinen, 2006 a): (1) health promotion, (2) the prevention of work-related and occupational diseases, (3) reduction in the impairment of work due to the diseases, (4) better support for disabled workers and (5) the promotion of work ability. A comprehensive solution for the aging challenge at the level of enterprise is the promotion of work ability during aging. This concept focuses on both human resources and working conditions. The core dimensions of human resources include health, physical and mental capacities and social functioning, competencies, as well as attitudes and values. The core dimensions of work cover the contents and demands of work, physical, ergonomic and psychosocial work environment, as well as management and leadership issues. Work ability is also connected to the microenvironment outside the workplace (family, relatives, friends, etc) as well as with the macro environment (infrastructure, services and other societal dimensions). The new core concept of work ability emphasizes the balance between human resources and work.

Workplace management with regard to job design and ergonomics may take the form of preventive measures or ones intended to compensate for physical decline. Recent literature on aging and the workforce reveals that older workers experience physical changes that may affect their work performance if their workplace is not accommodating. It has been noted that a "less physically and psychologically demanding environment might help keep older workers on the job longer" and might also increase the productivity of these workers.

There are a wide range of ways in which work induced illness or disability may be prevented by improved job design, for example by the elimination of heavy lifting or violent twisting movements, the provision of beneficial lighting and seating. For aging workers who are experiencing physical decline, it is possible to modify the workplace in order to assist them to maintain their productivity and, therefore, to remain in employment - for example, making changes in lighting levels to compensate for changes in eyesight or alterations to workstations in order to avoid arduous bending and reaching. Restructuring the workplace to accommodate older workers can also include the reduction of physically and mentally stressful tasks and more ergonomically designed work stations.

Managing different generations seems to be one of the greatest challenges for contemporary HRM. Very often, managers are facing difficulties in organizing work in age-mixed working teams, especially because there are many stereotyping assumptions concerning young and old employees. Younger usually believe, that many of the long-service staff resist organizational, management and technological changes, depicting older workers as having the attitude that 'we've always done it this way and will continue to do it this way' (Brooke, Taylor, 2005). The redeployment of older workers to positions using new technologies is often impeded by a perception that younger workers were more able to make skills transitions. Such age-bound assumptions, however, lead to misalignments between the actual skills required and the age segmentation of the labor force. This lead to relatively limited opportunities for skills development among older workers - the perception became a self-fulfilling prophecy. The deployment of younger workers in supervisory positions over older workers also leds to tensions, since young managers are usually perceived by older senior managers as lacking the skills and experience required for their supervisory positions.

One of the most important changes that need to take place to accommodate older workers is that of the workplace culture. Ageism in the workplace needs to be addressed, as older workers will make up a larger proportion of the workforce in the coming years. Consequently, the need to manage the relationships between the age groups is pointed out by more and more employers of different generations, who are getting aware of possibility of developing competitive advantages by achieving synergy effects of mixed-age workforce. Aging members of a working team are seen as valuable because they are able to add to the working environment a narrative depth based on experience. Managing different generations at work also adds to the improvement of working culture that may benefit from the members being of various ages and having different experiences. It is a challenge that requires new ways of management and working. 


\section{AGE MANAGEMENT IN SLOVENIAN COMPANIES: A COMPREHENSIVE MODEL}

Because of age discrimination, and a longstanding culture of early exit from employment, many organizations in Slovenia, both the workplace and the community, have no experience in positively targeting older workers. Therefore, those looking to respond to workforce aging usually start from a low or non-existent base.

Chart 1: Fields of Action - constituting a Comprehensive Age Management Model

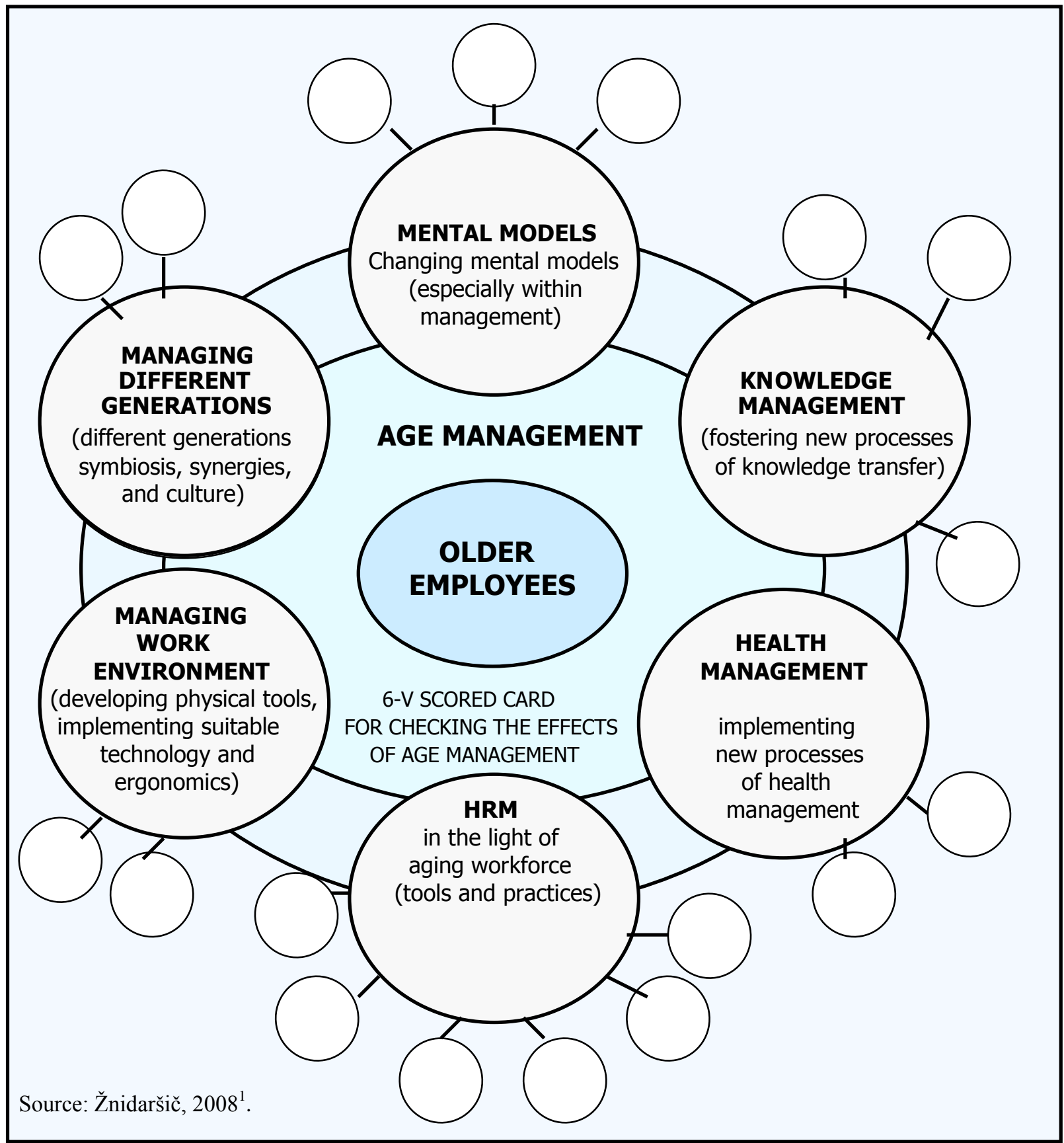

1 The model presented above was proven in practice within empirical research, conducted in 2007 (Žnidaršič, 2008). The model formation is based on the findings of a comprehensive review of a wide range of materials (ex. Ilmarinen, 2006; Leibold, 
With the aim to help beginners, we have developed a conceptual model, thus providing a useful base for further development of company-specific age management model that suits company needs the most. A key message is that when it comes to good practice, even very small changes can have a positive impact.

Although the six different dimensions (fields of action) of age management have been separated for purposes of developing the comprehensive age management model, in practice the boundaries between them are often blurred. This is not surprising: if an organization adopts HR policies that emphasize equal opportunities for older workers this orientation is likely to permeate other aspects of employment in the organization. However, our proposal for age management model at organizational level should be regarded not as a once-and-for-all achievement but as a range of possible interventions, from minor to major, that contribute to promoting the interests of both older workers and organizations. These interventions do not necessarily imply large financial outlays; on the contrary many important changes can be implemented at low cost. Implemented actions should be 'fit for purpose', that is, cost-effective and appropriate. It must be monitored and evaluated to ensure that it is achieving its goal. Even though, it is possible to implement very specific initiatives, such as the abolition of age limits in recruitment advertisements, without altering the approach to age management in the organization as a whole, the most efficient way of age management within a company is by developing the comprehensive age management model - being implemented through the broad age management strategy.

The strategic goal of the comprehensive age management model is to highlight the wide pool of possible measures that can be used by HRM to efficiently adopt to the aging workforce, and simultaneously follow the basic principle of personnel economics, so that age management would work to older workers' credit as well as it would work for the good of the company. The whole age management model is about measures, which enable older employees to remain employable (in the sense of productivity and in the sense of staying committed to the company). The model is the answer to many employers who are skeptical about retaining older workers, because it proposes how to deal with the elderly, so that they would have a chance to work, would be capable to prolong their working lives, they would enjoy their work and they would also want (and freely choose) to work longer.

The model is all about how to make an opportunity out of potential crisis. It is about how to efficiently master the challenges of aging, and simultaneously going beyond reactive management, but moving on the level of proactively implementing age management measures with the aim to turn the threats - connected with aging - to sound business opportunities.

\section{THE SIGNIFICANT ROLE OF AGE MANAGEMENT (MODEL): RESHAPING OMINOUS TRIANGLE TO PROMISING CIRCLE}

The comprehensive model we present it in this paper is certainly a good starting point for beginners, since it summarizes the broad pool of activities that can be considered (or implemented) by HRM when approaching older workers. However, managers can still be somehow skeptical about age management implementation as a sound business opportunity, especially in a global crisis period.

Our critical reflection should consider an economic aspect, too. We also need to take into account the economic effectiveness of organizational policies and organizational goals when the problem of aging and age management is discussed. From economic aspect, an important starting point for any firm is the productivity of any given employee (including older workers), in relation to their respective wage. Evers \& de Lange (2006) call this problem »the Bermuda Triangle « and the main idea is that if there is no balance between these three dimensions, an economic sense concerning the employment of older workers will disappear (like planes and ships do in the real Bermuda Triangle).

Voelpel, 2006; Naegele, Walker, 2006; Nunn, Wymer, Fidler, 2006; Remery et al., 2003; Taylor, 2006; Van Dalen, 2006; Vickerstaff et al., 2004; Walker, 1998), as well as on the results of recent research that has been done between Slovenian companies (top managers and HRM) and older workers (Žnidaršič, 2008). 


\section{Chart 2: The Bermuda Triangle}

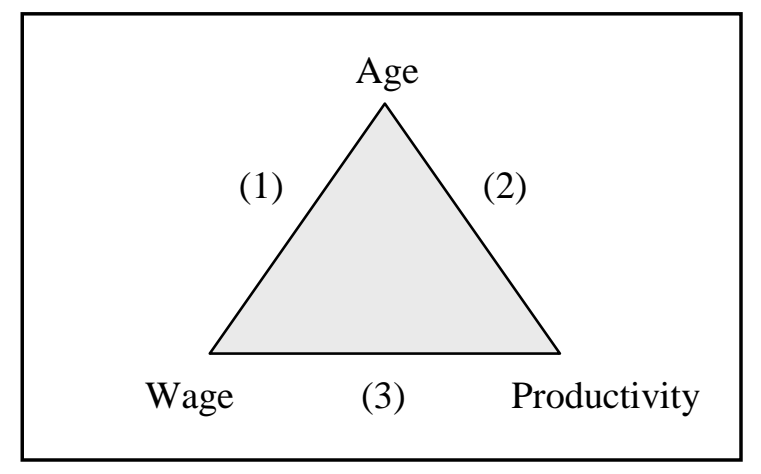

Source: Evers \& de Lange, 2006.

This triangle shows three important relationships (Evers \& Ester, 2008): (1) the relation between age and wage; this is called the age earnings profile - older workers are more expensive than younger workers, from the average earnings point of view (Lazear, 1998); (2) the age-productivity relation that points out the relative importance of wages in a sense of correlation with productivity of older workers - age-productivity profile is commonly expected to be graphically depicted as an inverse U-shaped curve ${ }^{2}$; (3) the relationship between wage and productivity - if higher wages are offset by equivalent higher productivity we may face the simple economic sense, however, we know that there is normally an imbalance between wages and productivity. At younger and older ages, employees have productivities below their wage level, and in their mid-ages, they make up for this by rendering far higher productivities than their respective wages would account for. When there is only limited external mobility, there is no big problem with this system. Over a life-time basis, the net productivity revenues will cover up the wage-expenses. However, as external mobility decreases with age, the firm-internal basis can be disrupted and employing older workers would seem »out of any economic sense«.

The relations from the »Bermuda triangle « call our attention to the fact that from economic perspective (is it a nation or an organization); there should be a correspondence between wage, age and productivity. Only then, stability is guaranteed. In the future, there will be of crucial importance especially for older workers (and their comparative advantages) and for their equal opportunities on labor market to better balance wages and productivity within each age group.

Until three corners of the triangle are out of balance (in economic sense), organizations will find themselves in a real stress to come with proper answers to the threats this will have on profitability and competitiveness (when the average age of the employees increases) (Evers, Ester, 2008). Consequently - retaining or employing older workers would definitely not be seen as sound business opportunity, but rather the opposite.

Nowadays (especially in the crisis situation and recession), it is very clear that the basic lows of personnel economics should not be neglected by HRM, consequently we already face bigger flexibility in labor costs. This can be done by flexible volumes (such as temporary work, dismissal procedures, flexible contracts, working overtime, and so on), and by flexible wages (Evers, Ester, 2008).

Actually, from motivation perspective, rather than putting great efforts into methods for decreasing wages (when balancing them with potential lower productivity), employers should think about how to raise productivity (motivation, commitment etc.) of older workers or at least how to sustain their quality and employability. Keeping

\footnotetext{
${ }^{2}$ Empirical evidence for this relationship - and particularly for the falling human capital levels at later ages - is however mixed (ex. Gelderblom, 2006; McEvoy \& Cascio, 1989; Skiold, 1998; Skirbekk, 2004;2006; Waldman, Avolio, 1986; Warr, 1994). First of all there is some studies pointing out that for particular skills no negative relationship with age can be found. But even if for some skills, such as the ability to perform physically demanding tasks, a negative relation with age can be established this may be compensated by acquiring other skills and more work experience.
} 
or even forcing more older workers to remain in the workforce is not enough. Employers should be willing to invest in workplaces that keep older workers productive, innovative, flexible, and with up-to-date skills. Consequently, firms are challenged to develop an 'older workers policy'. This is defined as the policy by which older workers keep working during a longer time in good health, highly motivated and highly productive (Evers \& de Lange, 2006). Lately, the older workers policies are gathered together within new term - age management. Nowadays, age management is of enormous importance and also a big challenge for companies (managers) if they want their prosperity and sustainable growth to be assured for today and also for the future.

On this point we need to position the comprehensive age management model between the central management activities and highlight its essential role in striving to reshape the ominous triangle into promising, sustainable circle (Chart 3). If we want older workers to work longer, we need to proactively adapt to their needs and ensure the sustainable level of their human capital - be it general or firm-specific. In an era of population aging, enabling older workers to update and secure their human capital, is of vital importance in developed countries, which can no longer afford to waste the human capital accumulated by older workers.

The fields of action that constitute the comprehensive model of active aging on the company level can enable certain company (and with time also the society) to grind off the edges or even to shape round its sharp triangle corners, into the smooth circle line. This can be achieved by balancing the productivity and wages of older workers, and thus enable »age« (depicted with the circle line around yin-yang symbol) »to work« (it means, enabling aging workforce to stay employable and able to prolong the working life). Just like in yin-yang circle where the black and white shapes within the circle represent the compatible interaction of two energies, which cause »everything « (represented with outer circle) to happen - one may assume that by implementing the policies that constitute age management model, older workers will remain employable and productive. Consequently, there will be better balance between wages and productivity, and »age will work«. An aging workforce will be put on the pedestal where it should be and instead of being seen as a burden (within the »Bermuda triangle « circumstances); it will be respected as a valuable asset. So, the realization of age management model would mean slowly (in stages) reshaping the ominous triangle into smooth yin-yang circle.

When "Bermuda triangle" represents »a problem«, age management model is »a tool« for solving it, and yin-yang circle is » a solution « that assumes »age« to happen, going beyond personnel economics from the viewpoint of employers, but implying benefits and workable reality also from the viewpoint of older employees.

\section{Chart 3: Age management model: The linking tie between »the Bermuda Triangle« and »Yin-Yang ${ }^{3}$ circle«}

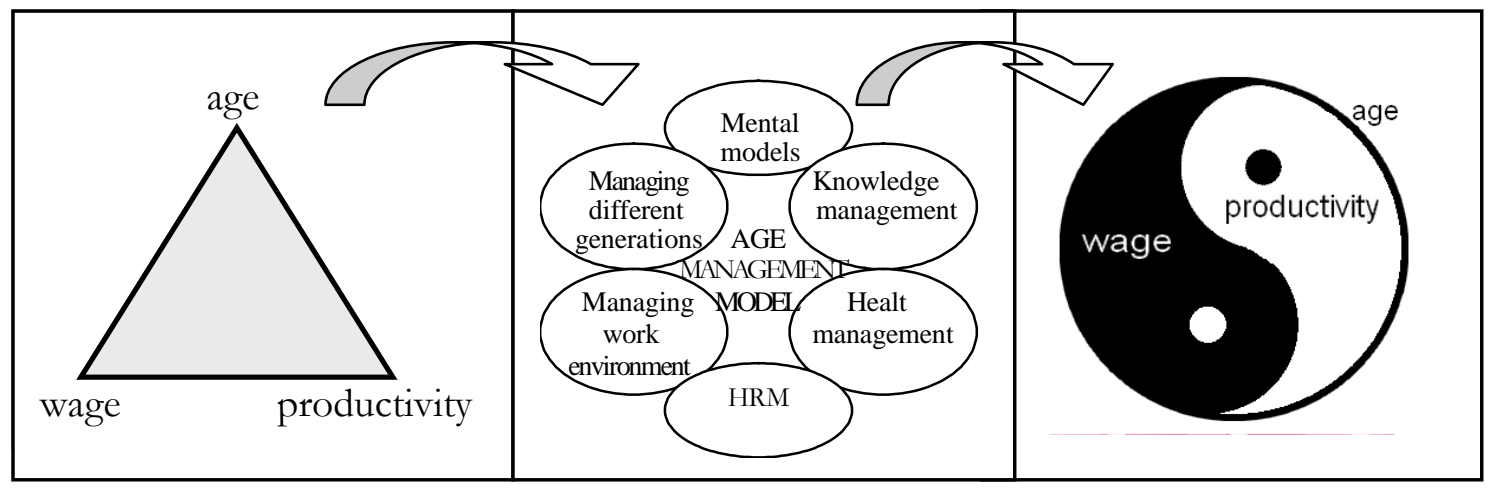

Source: the authors` model; also: Evers, Ester, 2008; Žnidaršič, 2008.

\footnotetext{
${ }^{3}$ Yin-Yang simbol represents the ancient Chinese understanding of how things work. The outer circle represents "everything", while the black and white shapes within the circle represent the interaction of two energies, called "yin" (black) and "yang" (white), which cause everything to happen. They are not completely black or white, just as things in life are not completely black or white, and they cannot exist without each other.
} 
There appear many challenging questions that are addressed to employers in the context of transforming triangle into circle, such as: (1) what are the reasons for not being inclined to employ or retain older workers; (2) do they invest in human capital maintenance of its older employees; (3) do they encourage training and lifelong learning for older workers; (4) do they adapt working environment and demands of certain workplace to capabilities that older workers possess; (5) which measures in general are they taking to retain older workers; (6) what are the main aims of implementing HRM measures targeting older employees; (7) can they actively improve productivity of older workers, so they will better match their higher earnings etc.

However, productivity can be highly influenced by HRM policies; it can be reinforced by appropriate wage systems. It also improves, for instance by increased training programs, by (preventive) implementing health management activities or by improved working conditions. Productivity can be raised also by combining different generations where knowledge sharing takes place.

Employees, on the other hand, should be able to prove that they have seriously worked on their employability level by spending energy to training, keeping fit, and so on (Evers, Ester, 2008). This is covered under $6-\mathrm{V}$ scored card for checking the effects of age management, including all six fields of action that constitute age management model on organizational level. If we want age management to become »workable reality « and actually accepted within companies as a sound business opportunity, the employers should permanently check its efficiency and constantly do the critical reflection concerning cost-benefit analysis of age management implementation process.

\section{FINAL RECOMMENDATIONS}

The first step in age management implementation process definitely involves combating age barriers, especially those that are based on certain attitudes and stereotypes. Although mindsets should primarily be changed among managers and employees within organizations, there are also various external stakeholders (government, suppliers, customer groups etc.) that need to be influenced through various tools, which include (Leibold, Voelpel, 2006): (1) lobbying tools; (2) managerial employee-engagement tools; (3) demonstration-effect tools; (4) project team diversity tools and (5) aging workforce debriefing tools.

Lobbying tools and negotiating mechanisms are needed to influence governmental legislation concerning age and workplaces, revenue and tax regimes, industry conventions, health treatment for the aged etc. Managerial employee-engagement tools are of vital importance while implementing age management in enterprises, since there is no doubt that engaged workers are more productive and contribute positively to financial success. Employee satisfaction is about sufficiency - enough pay, benefits, meaningful flexibility to combine work and life, and no major problems or sense of unfair treatment. Employee engagement goes beyond that, and is about passion, commitment and enthusiasm, it is about the willingness to invest personal time and efforts to help the enterprise succeed, simultaneously care deeply about the results. Managerial employee-engagement activities help managers to connect with employees and this is of vital importance when managing older workers. Demonstration-effect tools due to powerful associations are also helpful, since managers relate strongly to other companies and their experiences when concerning with the similar challenges. Project team diversity is of great importance; because mindset changes often occur when people from diverse back-grounds are put together (this also goes for age diversity in teams). Finally, there are aging workforce debriefing tools (or sessions) which illustrate the impact of age management activities on enterprise performance.

Our final recommendations for employers when striving to retain older workers would include the following strategies: (1) promoting greater awareness of older workers - employees and employers alike need to be educated about older workers and their contribution in the workplace; stereotypes and biases need to be eliminated; (2) promoting greater access to training for older adults and promoting active aging; (3) advancing the recruitment of older adults (since very few Slovenian organizations actively recruit older workers) - effective strategies for the recruitment of older workers include recruiting through non-traditional channels, developing a reputation as a good employer and recruiter of older workers; and offering flexible work arrangements that might be attractive to older adults; (4) working with government to promote anti-discrimination policies regarding human resource issues, such as recruitment, retention, and training opportunities for workers of all ages; (5) increasing recognition of credentials 
within Slovenia in order to facilitate labor movement ( i.e., from areas with a surplus of labor to areas with labor shortages); (6) sharing good practices among companies; (7) educating employers and promoting the age management model development (and its implementation in day-to-day practice) and putting efforts into disseminating the awareness about the importance of proactively responding on aging-workers challenges, thus enabling the sustainable prosperity for enterprises and for society as a whole.

\section{CONCLUSIONS}

The national strategic and other documents, especially in the field of employment, indicate that the government of the Republic of Slovenia is aware of the problems arising from the aging of the Slovenian population and its workforce.

In order to achieve the EU goal of the $50 \%$ employment rate of people aged 55 - 64 by 2010, the macroeconomic approach is not enough. Even though many documents and acts were passed at a government level, experts suggest that age management on a company level has to be enforced. For increasing employment of the older workforce, policy measures should be (more) obligatory for employers and should also be aimed at awareness building and attitude changing of employers.

HR managers are starting to familiarize themselves with the concepts, methods and tools, but only a few large companies have gained some experience in this matter (Žnidaršič, 2008). The conclusion of one of our recent research (Žnidaršič, 2008) is very clear; employers will have to develop more effective ways of managing their aging workforce to maintain operational continuity. It is very clear, that the aging of Slovenia's workforce is likely to have numerous human resource implications over the coming years. These challenges will be in the areas of: workforce planning; retention of older workers; health, safety \& ergonomic strategies; work environment strategies; as well as recruitment and training methods.

Since age management in Slovenia is still in its "kindergarten" years, and with the aim to help beginners, we have developed a conceptual model, thus providing a useful base for further development of company-specific age management model that suits to the company needs the most.

The strategic goal of the comprehensive age management model that is presented in this paper is to highlight the wide pool of possible measures that can be used by HRM to efficiently adopt to the aging workforce, and simultaneously follow the basic principle of personnel economics, so that age management would work to older workers' credit as well as it would work for the good of the company. The whole age management model is about measures, which enable older employees to remain employable (in the sense of productivity and in the sense of staying committed to the company). The model is the answer to many employers who are skeptical about retaining older workers, because it proposes how to deal with the elderly, so that they would have a chance to work, would be capable to prolong their working lives, they would enjoy their work and they would also want (and freely choose) to work longer. The model is all about how to make an opportunity out of potential crisis. It is about how to efficiently master the challenges of aging, and simultaneously going beyond reactive management, but moving on the level of proactively implementing age management measures with the aim to turn the threats - connected with aging - to sound business opportunities.

With age management model implementation into day-to-day business practice, each company would enable its older workers to stay active, to maintain their workability and employability and even going beyond while enriching their human capital with age. An efficient age management can literally transform the role of older workers in organization, from a burden to valuable asset, a benefit.

Our paper highlights the essential role of age management within general HRM policies in striving to reshape the ominous triangle (in most cases representing the relationship between wage, age and productivity that is out of balance) into promising, sustainable circle, which assume more of less perfect balance between age, wage and productivity. Only then the retention of older workers would seem not only of macro-economic importance (actually, necessity in the sense of maintaining welfare state sustainability) but also the vital source of microeconomic benefits. 
The main message concerning the development and implementation of the model is that each organization should develop the fields (elements - constituting the model), which would be of the greatest importance and could bring the most value added in the sense of managing older workers for the good of both, the company and its employees. It means that there is no simple and »one size fits all« recipe where and how to begin, just like there is no single remedy to resolve problems concerning older workers. When implementing age management measures, an organization should be flexible (in time and in space), simultaneously adapting to its needs and also responding to outer circumstances that are changing continuously. We can talk about contingency model of active aging at workplace and the message of this paper - presenting the organizational model of active aging - is that each organization should develop its own age management model that would suit the company needs (within certain circumstances) the best.

\section{REFERENCES}

1. Brooke L., Taylor P.: Older Workers and Employment: Managing Age Relations. Ageing and Society, 25(3), 2005. Pp.: 415-430.

2. Brooke L.: Human resource costs and benefits of maintaining a mature-age workforce. International Journal of Manpower, Vol. 24, No. 3, 2003. Pp.: 260-283.

3. DeLong D. W.: Lost Knowledge: Confronting the Threat of an Aging Workforce. New York: Oxford University Press, 2004. 258 pgs.

4. $\quad$ Dimovski V., Žnidaršič J., 2006: Od koncepta zgodnjega upokojevanja k strategiji aktivnega staranja. Kakovostna starost, 2006, letn. 9, št. 1, pp. 2-14. In Slovenian.

5. Dunn S.: Effective Strategies for Training Older Workers. V Beatty P. T., Visser R. M. S. (Edit.): Thriving on an Aging Workforce: Strategies for Organizational and Systemic Change. Malabar, Florida: Krieger Publishing Company, 2005. Pp.: 70-80.

6. EU25 population rises until 2025, then falls. Population prejections 2004-2050. Eurostat news release 48/2005, Luxembourg: Eurostat Press Office, 2005.

7. European Commission: Employment in Europe 2007. Luxembourg: Office for Official Publications of the European Communities, 2007. 318 pgs.

8. $\quad$ Evers G.H.M., de Lange W.A.M.: Older workers, equality and productivity. Paper presented at the Industrial Relations in Europe Conference (IREC), Ljubljana, 31 August - 2 September 2006. 14 pgs.

9. Evers G.H.M., Ester P.: Ageing workforce, human capital and the Bermuda triangle: An interdependent analysis. Paper presented at the World Ageing \& Generations Congress 2008, St. Gallen, August 2008.

10. Gelderblom, A.: The relationship of age with productivity and wages. In: European Commission (2006): Ageing and employment: Identification of good practice to increase job opportunities and maintain older workers in employment. Brussels: European Commission, 2006. Pp.: 67-84, 216-228.

11. Ilmarinen J.: The ageing workforce - challenges for occupational health. Occupational Medicine, 56(6), 2006 a. Pp.: 362-364.

12. Ilmarinen J.: Towards a longer worklife! Ageing and the quality of worklife in the European Union. Finnish Institute of Occupational Health. Helsinki: Ministry of Social Affairs and Health, 2006. 467 pgs.

13. Jouhette S., Romans F.: Labour market. Statistics in focus - Population and social conditions - 9/2005. Eurostat, 2005. URL: http://epp.eurostat.cec.eu.int/cache/ITY_OFFPUB/KS-NK-05-009/EN/KS-NK-05009-EN.PDF

14. Jouhette S., Romans F.: Labour market. Statistics in focus - Population and social conditions - 13/2006. Eurostat, 2006. URL:http://epp.eurostat.ec.europa.eu/cache/ITY_OFFPUB/KS-NK-06-013/EN/KS-NK06-013-EN.PDF

15. Kajzer A.: Delne zaposlitve so priložnost za prožnejši trg dela. Ljubljana: Finance, petek, 12. Avgust 2005, št. 156, p. 9. In Slovenian.

16. Kajzer A.: Fleksibilnost trga dela - o pojmu, dejavnikih in pomenu za zaposlenost in brezposelnost. Ljubljana: Urad Republike Slovenije za makroekonomske analize in razvoj. IB revija. Revija za strokovna in metodološka vprašanja trajnostnega razvoja. Št. 1-2 / letnik XXXVIII / 2004, pp. 108-116. In Slovenian.

17. Lazear E. P.: Personnel Economics for Managers. New York: John Wiley \& Sons, 1998. 538 pgs.

18. Leibold, M., Voelpel, S.: Managing the Aging Workforce; Challenges and Solutions. Publicis Corporate Publishing and Wiley, 2006. 244 pgs. 
19. Mandl I., Dorr A., Oberholzner T.: Age and employment in the new Member States. European Foundation for the Improvement of Living and Working Conditions. Luxembourg: Office for Official Publications of the European Communities, 2006. 84 pgs.

20. McEvoy G.M. \& W.F. Cascio: Cumulative evidence of the relationship between employee age and job performance. Journal of Applied Psychology, 74(1), 1989. Pp.: 11-17.

21. Naegele G., Walker A.: A guide to good practice in age management. Foundation for the Improvement of Living and Working Conditions. Luxembourg: Office for Official Publications of the European Communities, 2006. 36 pgs.

22. Nunn A., Wymer P., Fidler Y.: Ageing \& Working. A report prepared for: The Fair Play for Older Workers Partnership. Leeds: Policy Research Institute, Leeds Metropolitan University, 2006. 69 pgs.

23. Pušnik K. et al.: National Research Report Slovenia Employment Initiatives for an Ageing Workforce in the New Member States Plus Romania and Bulgaria. Study on behalf of The European Foundation for the Improvement of Living and Working Conditions. Maribor: Institute for entrepreneurship and small business management, Faculty of Economic and Business, University of Maribor, 2006. 51 pgs.

24. Remery C. et al.: Managing an aging workforce and a tight labor market: views held by Dutch employers. Population Research and Policy Review, 22, 2003. Pp. 21-40.

25. Roland L.: The Age Chasm: Successfully Managing Age in Your Organisation. Drake Whitepaper Vol. 2, No. 5. Melbourne: Drake International, 2004.

26. Skiold L.: Older workers can be as effective as young ones. Working Life Newsletter No. 2. from the National Institute for Working Life. Stockholm: Arbetslivsinstitutet, 1998.

27. Skirbekk V.: Age and Individual Productivity: A Literature Survey. Vienna Yearbook of Population Research 2004 (Pp.: 133-153). Vienna: Austrian Academy of Sciences, Vienna Institute of Demography, 2004.

28. Skirbekk V.: Age and Productivity. Speaker's Presentation on Special Session on Productivity and Wages of Older Workers at the 2nd World Ageing and Generations Congress, 27. - 29. September 2006, St. Gallen, Switzerland.

29. Taylor P.: Employment initiatives for an ageing workforce in the EU15. European Foundation for the Improvement of Living and Working Conditions. Luxembourg: Office for Official Publications of the European Communities, 2006. 98 pgs.

30. Van Dalen et al.: Dealing with an ageing labour force: What do European employers expect and do? The Hague: The Netherlands Interdisciplinary Demographic Institute (NIDI), 2006. 47 pgs.

31. Van de Casteele A.: Early Retirement: Disease of the European Continent? AARP Newsletter. Washington D.C.: AARP, 2004.

32. Vickerstaff S. et al.: Happy retirement?: The impact of employer's policies and practice on the process of retirement. Bristol: The Policy Press / The Joseph Rowntree Foundation, 2004. 43 pgs.

33. Waldman D. A. \& Avolio B. J.: A meta-analysis of age differences in job performance. Journal of Applied Psychology, 71 (1986), Pp: 33-38.

34. Walker A.: Managing an Ageing Workforce. A Guide to Good Practice. The European Foundation for the Improvement of Living and Working Conditions, 1998. 24 pgs.

35. Warr P.: Research into the work performance of older employees. The Geneva Papers on Risk and Insurance, no. 73 (1994), Pp: 472-480.

36. Žnidaršič J.: Age management: The Organizational Model of Active Ageing. Doctoral Dissertation. University of Ljubljana, Faculty of Economics, 2008. 362 pgs. In Slovenian. Title in Slovenian: Management starosti: organizacijski model aktivnega staranja. 